\title{
Free Radical Scavenging Activities and Neuro-protective Effects of Extracts from Juniperus rigida Sieb. Fruit
}

\author{
Hyun Woo Kang*, Sang Jae Kwak \\ Department of Korean Food \& Culinary Arts, Youngsan University, Busan, 48015, Korea \\ *Corresponding author: khw7200@ysu.ac.kr
}

Received December 12, 2018; Revised January 19, 2019; Accepted March 02, 2019

\begin{abstract}
The antioxidative activity of extracts from Juniperus rigida Sieb. Fruit (JRSF) was evaluated by measuring 1,1-diphenyl-2-picrylhydrazyl (DPPH), hydroxyl and alkyl radical scavenging activity using an electron spin resonance (ESR) spectrometer. The free radical scavenging activity of the extract was dose dependant manner, and the $\mathrm{IC}_{50}$ value on $\mathrm{DPPH}$, hydroxyl and alkyl radical at $16.84,82.35$ and $52.27 \mu \mathrm{g} / \mathrm{mL}$ respectively. In addition, evaluated the protection effect on $\mathrm{H}_{2} \mathrm{O}_{2}$-induced oxidative damage in PC-12 cells via propidium iodide (PI) staining using a flow cytometer. JRSF extract decreased cell death in PC-12 cells due to $\mathrm{H}_{2} \mathrm{O}_{2}$-induced oxidative damage in a dose-dependent manner. These results suggest that JRSF extract exhibit antioxidative activity against oxidative stress on PC-12 cells.
\end{abstract}

Keywords: Juniperus rigida Sieb. fruit, antioxidant, free radical, PC-12 cells, flow cytometer

Cite This Article: Hyun Woo Kang, and Sang Jae Kwak, "Free Radical Scavenging Activities and Neuro-protective Effects of Extracts from Juniperus rigida Sieb. Fruit." Journal of Food and Nutrition Research, vol. 7, no. 3 (2019): 187-190. doi: 10.12691/jfnr-7-3-2.

\section{Introduction}

Reactive oxygen-mediated modification of DNA, proteins, lipids and small cellular molecules is associated with a number of pathological processes, including atherosclerosis, arthritis, diabetes, cataractogenesis, muscular dystrophy, pulmonary dysfunction, inflammatory disorders, ischemia-reperfusion tissue damage and neurological disorders such as Alzheimer's disease [1]. Free radical scavenger is a preventive antioxidant. The term antioxidant is defined as any substance that, when present at low concentrations compared to that of an oxidizable substrate, significantly delays or inhibits oxidation of that substrate [2]. Antioxidants can act at different levels in an oxidative sequence. This may be illustrated by considering one of the many mechanisms by which oxidative stress can cause damage by stimulating the free radical chain reaction of lipid peroxidation [3]. Free radical chain reactions within a material could be inhibited by adding chemicals that retard the formation of free radicals, by introducing substances that retard the formation of free radicals or by introducing substances that compete for the existing radicals and remove them from the reaction medium [3]. Many synthetic antioxidants such as butylated hydroxyanisole (BHA), butylated hydroxytoluene (BHT), tertiary-butylhydroquinone (t-BHQ) and propyl gallate (PG) may be used to retard lipid peroxidation in a lot of fields $[3,4]$. Therefore, search for natural antioxidants as alternatives to synthetic ones is of great interest among researchers.

Juniperus rigida Sieb. (JRS), is mainly grown in Asia $[5,6]$. The fruits and leaves of this tree have been traditionally used in folk medicine for the treatment of neuralgia, dropsy, and gout [7]. Pharmacologically, the phenolic compounds have been reported to inhibit NO production in LPS-induced RAW264.7cells [8]. However, the free radical scaveingin antivities of JRSF has not been evaluated until now.

Thus, the present study aimed to investigate the free radical scavenging activities of extracts from JRSF by ESR spectroscopy and their possible protective effects on PC-12 cells against oxidative stress.

\section{Materials and Methods}

\subsection{Materials}

Juniperus rigida Sieb. Fruit (JRSF) was purchased from a local market (Chungju, Korea). 1,1-diphenyl-2picrylhydrazyl (DPPH), 5,5-Dimethyl-1-pyrroline N-oxide (DMPO), 2,2-azobis (2-amidinopropane) hydrochloride (AAPH), (4-pyridyl-1-oxide)-N-tert-butylnitrone (4-POBN) were purchased from Sigma Chemical Co. (St Louis, USA), and pBR 322 DNA was procurred from Fermentas (Hanover, MD). Dulbecco's modified Eagle's medium (DMEM), fetal bovine serum (FBS), penicillin, and streptomycin were purchased from Hyclone (Logan, UT, USA). All other reagents were of the highest grade available commercially. 


\subsection{DPPH Radical Scavenging Activity}

DPPH radical scavenging activity was measured using the method described by Nanjo et al. [9]. An ethanol solution of $60 \mu \mathrm{L}$ of each sample (or ethanol itself as control) was added to $60 \mu \mathrm{L}$ of DPPH $(60 \mathrm{mM})$ in ethanol solution. After mixing vigorously for $10 \mathrm{~s}$, the solution was then transferred into a $100 \mathrm{~mL}$ quartz capillary tube, and the scavenging activity of JRSF extract on DPPH radical was measured using a JES-FA ESR spectrometer (JEOL Ltd., Tokyo, Japan). ESR spectrum was measured on an ESR spectrometer exactly 2 min later. Experimental conditions were as follows: central field, $3475 \mathrm{G}$; modulation frequency, $100 \mathrm{kHz}$; modulation amplitude, $2 \mathrm{G}$; microwave power, $5 \mathrm{~mW}$; gain, $6.3 \times 10^{5}$ and temperature, $298 \mathrm{~K}$.

\subsection{Hydroxyl Radical Scavenging Activity}

Hydroxyl radicals were generated by iron-catalyzed Haber-Weiss reaction (Fenton driven Haber-Weiss reaction) and the generated hydroxyl radicals rapidly reacted with nitrone spin trap DMPO [10]. The resultant DMPO-OH adducts was detectable with an ESR spectrometer. JRSF extract $(0.2 \mathrm{~mL})$ with various concentrations was mixed with DMPO (0.3 M, $0.2 \mathrm{~mL}), \mathrm{Fe}_{2} \mathrm{SO}_{4}(10 \mathrm{mM}, 0.2 \mathrm{~mL})$ and $\mathrm{H}_{2} \mathrm{O}_{2}(10 \mathrm{mM}, 0.2 \mathrm{~mL})$ in a phosphate buffer solution (pH 7.2), and then transferred into a $100 \mathrm{~mL}$ quartz capillary tube. After $2.5 \mathrm{~min}$, the ESR spectrum was recorded using an ESR spectrometer. Experimental conditions were as follows: central field, $3475 \mathrm{G}$; modulation frequency, $100 \mathrm{kHz}$; modulation amplitude, $2 \mathrm{G}$; microwave power, $1 \mathrm{~mW}$; gain, $6.3 \times 10^{5}$ and temperature, $298 \mathrm{~K}$.

\subsection{Alkyl Radical Scavenging Activity}

Alkyl radicals were generated by AAPH. The PBS (pH 7.4) reaction mixtures containing $40 \mathrm{mM}$ AAPH, $40 \mathrm{mM}$ 4-POBN and indicated concentrations of tested samples, were incubated at $37^{\circ} \mathrm{C}$ in a water bath for $30 \mathrm{~min}$, and then transferred to a $60 \mu \mathrm{L}$ Teflon capillary tube. The spin adduct was recorded on an ESR spectrometer. Measurement conditions were as follows: central field, $3475 \mathrm{G}$; modulation frequency, $100 \mathrm{kHz}$; modulation amplitude, $2 \mathrm{G}$; microwave power, $1 \mathrm{~mW}$; gain, $6.3 \times 10^{5}$ and temperature, $298 \mathrm{~K}$ [11].

\subsection{Cell Culture}

PC-12 cells were cultured and maintained in DMEM supplemented with penicillin $(100 \mathrm{U} / \mathrm{mL})$, streptomycin $(100 \mu \mathrm{g} / \mathrm{mL})$ and FBS (10\%) and maintained at $37^{\circ} \mathrm{C}$ under a humidified atmosphere with $5 \% \mathrm{CO}_{2}$. All the treatments were performed at $30 \%$ confluence.

\subsection{Apoptosis Analysis}

The PC-12 cells were seeded at $2 \times 10^{5}$ cells/well in 6 -well plates in a complete medium, DMEM with $10 \%$ FBS. After $24 \mathrm{~h}$ incubation in a humidified 5\% (v/v) $\mathrm{CO}_{2}$ /air environment at $37^{\circ} \mathrm{C}, 990 \mu \mathrm{L}$ of the extract solution in DMEM was transferred to the well to give a final concentration of $\mathrm{mg} / \mathrm{mL}$. Following $1 \mathrm{~h}$ incubation with the extracts, $10 \mu \mathrm{L}$ of $100 \mathrm{mM}$ hydrogen peroxide was added the medium. After $24 \mathrm{~h}$ the cell was harvested, and the harvested cells were suspended in ethanol with $0.5 \%$ Tween-20 and left for $24 \mathrm{~h}$ at $4^{\circ} \mathrm{C}$. The cells were then harvested by centrifugation and re-suspended in $1.0 \mathrm{~mL}$ of PBS with $0.05 \mathrm{mg} / \mathrm{mL}$ of propidium iodide and $10 \mu \mathrm{g} / \mathrm{mL}$ of RNase A and incubated at $37^{\circ} \mathrm{C}$ for $30 \mathrm{~min}$. The analysis of apoptotic cell death was performed by measuring the hypodiploid DNA contents using a flow cytometer (FACS-caliber, Becton Dickinson, NJ) [12].

\subsection{Statistical Analysis}

Study data are expressed as mean \pm standard error of mean (SEM). Statistical analyses of differences between treatment groups were conducted using Student's $t$-test for paired data, and $p<0.05$ was considered to have statistical significance. All analyses were carried out in triplicate using Graph Pad Prism software version 4.00 (Graph Pad Software Inc., San Diego, CA).

\section{Results and Discussion}

DPPH radical is a stable free radical, which has been used to evaluate free radical scavenging activity of natural antioxidants. In this study, the DPPH radical scavenging activity of extract from JRSF was shown in Figure 1A. JRSF extract was observed scavenging activity of 42.36, 66.82 and 81.35 at the concentrations of 15.625, 31.25 and $62.5 \mu \mathrm{g} / \mathrm{mL}$ on DPPH radical, respectively, In addition, the $\mathrm{IC}_{50}$ values was $16.84 \mu \mathrm{g} / \mathrm{mL}$. Hydroxyl radicals generated in the $\mathrm{Fe}^{2+} / \mathrm{H}_{2} \mathrm{O}_{2}$ system were trapped by DMPO, forming a spin adduct detected by an ESR spectrometer. Here. the extract from JRSF was observed that the hydroxyl radical scavenging activities were 27.61, 40.29 and $77.76 \%$ at $31.25,62.5$ and $125 \mu \mathrm{g} / \mathrm{mL}$, respectively, and the $\mathrm{IC}_{50}$ value was $82.35 \mu \mathrm{g} / \mathrm{mL}$ (Figure 1B). The alkyl radical spin adduct of 4 -POBN/free radicals was generated from AAPH at $37^{\circ} \mathrm{C}$ for $30 \mathrm{~min}$, and the decrease of ESR signals was observed with the dose increment of the extract from JRSF. alkyl radical scavenging activities of the extract from JRSF were 36.50, 56.11 and $88.66 \%$ at 31.25, 62.5 and $125 \mu \mathrm{g} / \mathrm{mL}$, respectively, and the $\mathrm{IC}_{50}$ value was $52.27 \mu \mathrm{g} / \mathrm{mL}$ (Figure $1 \mathrm{C}$ ). In recent, there is a continuing search for better and more effective antioxidants, expecially those from natural sources. There is a close association between chronic inflammation and cancer. Evidence for this comes from epidemiological studies, linking reactive species overload diseases to high cancer risk [13]. At a molecular level, free radicals produced during chronic inflammation, can induce deleterious gene mutation and post-translational modifications of key cancer-related proteins [14]. The pro-cancerous outcome of chronic inflammation is increased DNA damage. A critical mechanism toward cancer associated with reactive species overload diseases is the attack of cancer genes and proteins, RNA, and lipids by reactive nitrogen and oxygen species [14]. Therefore, a key treatment strategy is to reduce the free radical load to diminish these pro-cancerous mechanisms. Free radicals are atoms or groups of atoms with an odd (unpaired) number of electrons and can be formed when oxygen interacts with certain molecules. Once formed these highly 
reactive radicals can start a chain reaction, like dominoes. These results indicate that the extract from JRSF possess scavenging activity against DPPH, hydroxyl and alkyl radicals. The neuroprotective effect of JRSF extracts was determined by apoptosis analysis using a flow cytometer.
The cells were treated with the extracts prior $1.0 \mathrm{mM}$ hydrogen peroxide, the percentage of apoptotic cells was observed $35.31 \%$ at $1.0 \mathrm{mM}$ hydrogen peroxide, while the percentages of JRSF extracts treated cells were 27.55 and $19.36 \%$ at 62.5 and $125 \mu \mathrm{g} / \mathrm{mL}$, respectively (Figure 2).

A

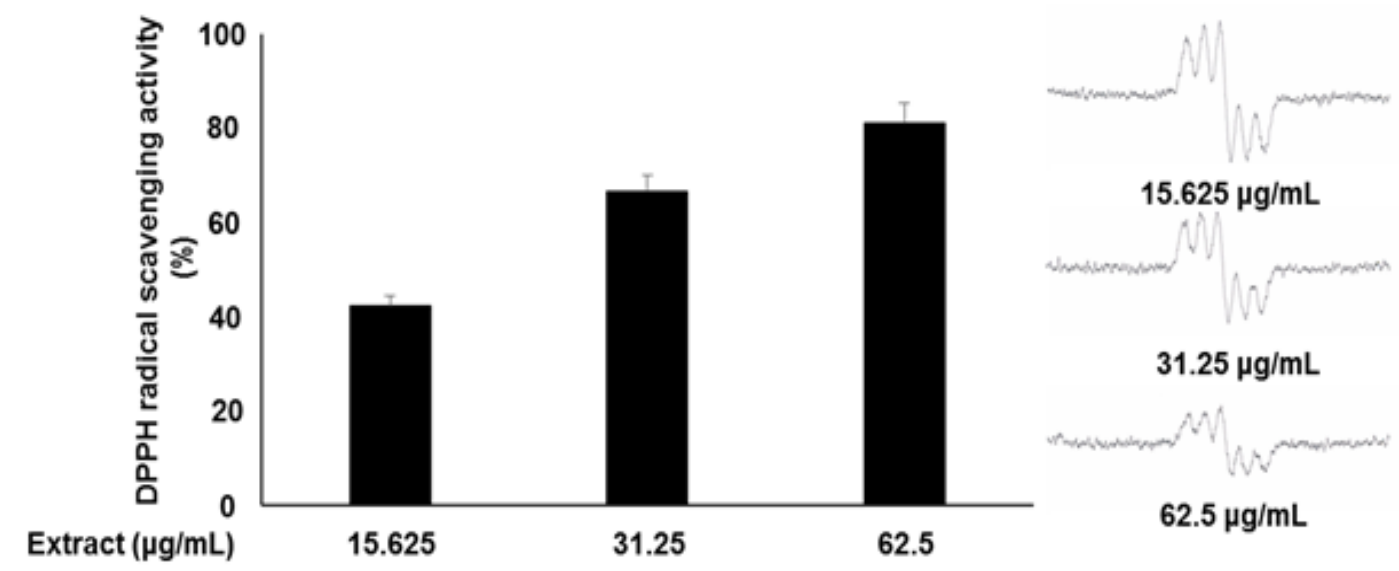

B
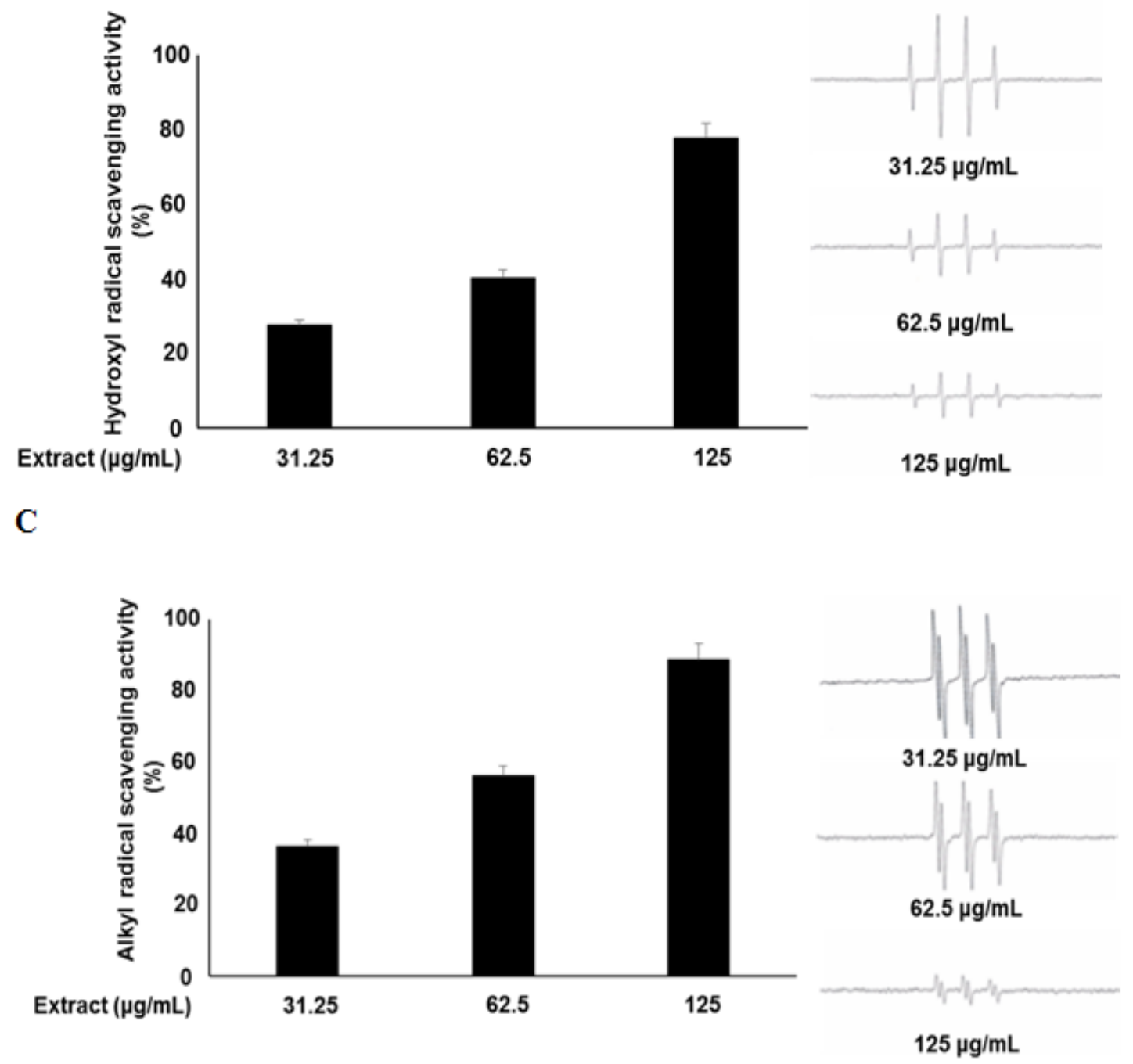

Figure 1. DPPH (A), hydroxyl (B), and alkyl (C) radical scavenging activity (left) and spectra (right) of extract from JRSF using ESR spectroscopy. Means \pm SD of determinations were acquired from triplicate experiments Data are presented as mean \pm S.E.M. $(n=3)$ for three independent experiments. жNot significantly different from that of the control group. Significance was determined by Student’s $t$-test. ${ }^{*} p<0.05$. 


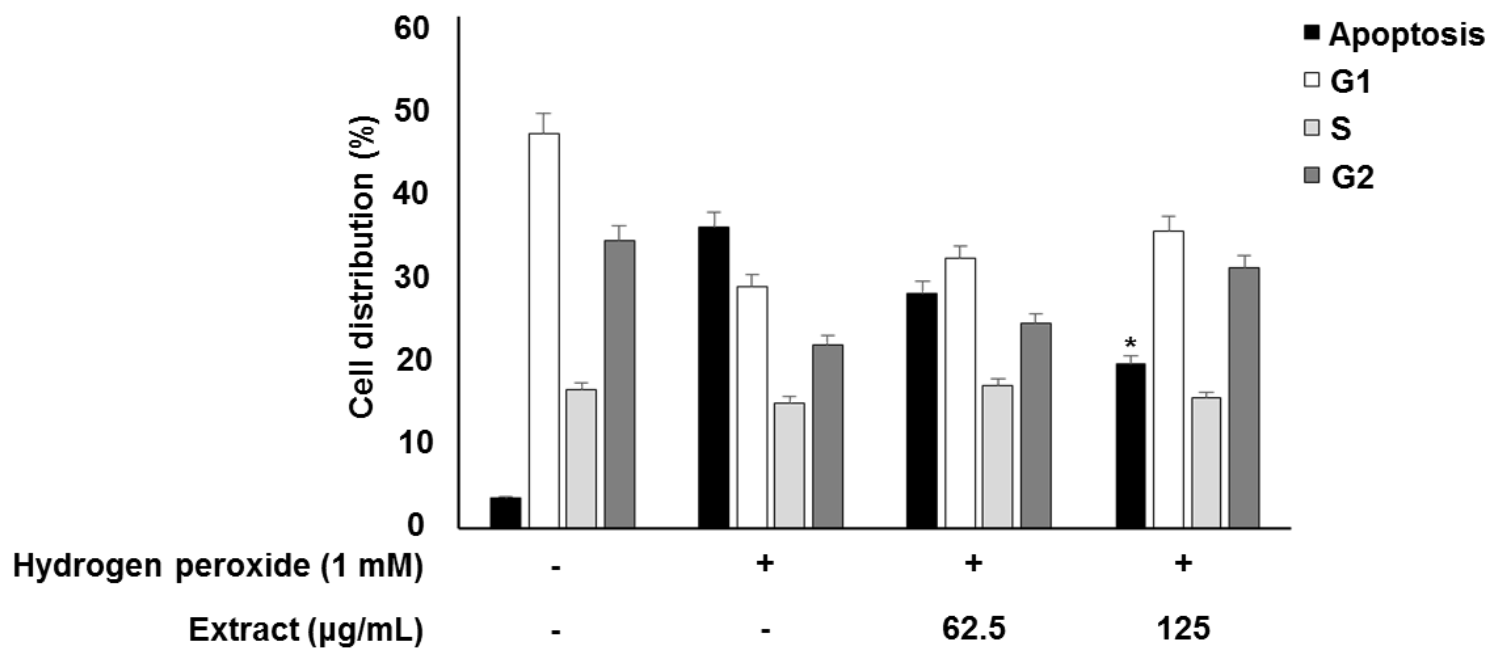

Figure 2. Cell death and cell cycle of PC-12 cells after treatment with extract of JRSF prior to hydrogen peroxide (1 mM) treatment. Means \pm SD of determinations were made in triplicate experiments. ${ }^{*}(\mathrm{p}<0.05)$ and ${ }^{* *}(\mathrm{p}<0.01)$ are significantly different as analyzed by paired t-test that compared the oxidative stress group with the extract of JRSF treated group

The result of this study suggests that JRSF extract could be utilised to develop physiologically functional foods. In addition, it is expected that this will contribute to increase interest and potential applications of bioactive materials.

\section{Conclusions}

In the present study, we focused on natural water-soluble free radical scavenger from ectract of JRSF. Their free radical scavenging activities were evaluated in different reactive oxygen species assays including DPPH, hydroxyl and Alkyl radical scavenging assays by an ESR spectrophotometer. Also, JRSF extract protect neuronal cells against hydrogen peroxide-induced oxidative damage. Overall, this natural product has the potential to be developed into new biomaterials.

\section{Acknowledgments} 2018.

This research was supported by Youngsan University in

\section{References}

[1] Frlich, I., and Riederer, P., "Free radical mechanisms in dementia of Alzheimer type and the potential for antioxidative treatment” Drug Research 45, 443-449. 1995.

[2] Halliwell, B., and Gutterridge, J.M.C., "Free radicals in biology and medicine (2nd ed.). Oxford: Clarendon Press”, 1989.

[3] Kim, S.K., Kim, Y.T., Byun, H.G., Park, P.J., and Ito, H.,
"Purification and characterization of antioxidative peptides from bovine skin” J Biochem Mol Biol 34, 219-224. 2001.

[4] Wanita, A., and Lorenz, K., "Antioxidant potential of 5-Npentadecylresorcinol” J Food Process Preserv 20, 417-429. 1996.

[5] Adams, R.P., Chu, G., and Zhang, S., "Comparisons of the volatile leaf oils of Juni-perus rigida Mig. From north eastern China, Korea and Japan” J Essent Oil Res 7, 49-52. 1995.

[6] Lee, Y., Kim, J., Kim, H., Sohn, E., Kim, C., Jeong, I., Jo, K., Kim, J., and Kim, J., "Anti-lipase and lipolytic activities of EtOH extract from Juniperus rigida” Korean J Pharm 41, 216-220. 2010.

[7] Woo, K.W., Choi, S.U., Park, J.C., and Lee, K.R., "A new lignin glycoside from Juni-perus rigida” Arch Pharm Res 34, 2043-2049. 2011.

[8] Jeong, E., Seo, H., Yang, H., Kim, J., Sung, S., and Kim, Y., "Anti-inflammatory phe- nolics isolated from Juniperus rigida leaves and twigs in lipopolysaccharide- stimulated RAW264.7 macrophage cells" J Enzym Inhib Med Chem 27, 875-879. 2012.

[9] Nanjo, F., Goto, K., Seto, R., Suzuki, M., Sakai, M., and Hara, Y., "Scavenging effects of tea catechins and their derivatives on 1,1,-diphenyl-2-picrylydrazyl radical” Free Rad Bio Med 21, 895902. 1996.

[10] Rosen, G.M., and Rauckman, E.J., "Spin trapping of superoxide and hydroxyl radicals” In Methods in Enzymology Packer, L., Ed.; Academic Press: Orlando, FL, Vol. 105, 198-209. 1984.

[11] Lee, S.J., Kim, E.K., Oh, H.J., Kwon, H.J., Hwang, J.W., Moon, S.H., and Park P.J., "Free radical scavenging activity and protective effect against $\mathrm{H} 2 \mathrm{O} 2$-induced stress in neuronal cells of enzymatic extracts from Sarcodon aspratus” Korean J Med Crop Sci 19(2), 77-82. 2011.

[12] Lee, S.J., Kim, Y.S., Hwang, J.W., Kim, E.K., Moon, S.H., Jeon, B.T., Jeon, Y.J., Kim, J.M., and Park, P.J., "Purification and characterization of a novel antioxidative peptide from duck skin by-produc ts that protects liver against oxidative damage”, Food Res Int 49 (1). 285-295. 2012.

[13] Hofseth, L.J., and Ying, L., "Identifying and defusing weapons of mass inflammation in carcinogenesis” Biochim Biophys Acta 1765, 74-84. 2006.

[14] Hussain, S.P., Hofseth, L.J., and Harris, C.C., "Radical causes of cancer” Nat Rev Cancer 3, 276-285. 2003. 